\title{
Serotonin Transporter Gene Polymorphism Associated with Short-Term Treatment Response to Venlafaxine
}

\author{
Sang-Hyuk Lee ${ }^{a}$ Tae Kyou Choi ${ }^{b}$ Eun Lee ${ }^{b}$ Jeong-Ho Seok ${ }^{b}$ Sung Hee Lee ${ }^{c}$ \\ Hong Shick Lee ${ }^{b}$ Se Joo Kim ${ }^{b}$ \\ a Department of Psychiatry, CHA Bundang Medical Center, CHA University School of Medicine, Seongnam, and \\ ${ }^{b}$ Department of Psychiatry and Institute of Behavioural Science in Medicine and ' Department of Pharmacology, \\ Yonsei University College of Medicine, Seoul, South Korea
}

\section{Key Words}

5-HTTLPR polymorphism • Treatment response •

Venlafaxine $\cdot$ Genetics

\begin{abstract}
Background: Polymorphisms of serotonin transporter, especially serotonin transporter linked promoter region (5HTTLPR) and serotonin transporter intron 2 variable number tandem repeat (5-HTTVNTR), have been suggested to be associated with treatment response to selective serotonin reuptake inhibitors. However, there have been only few reports of the association between 5-HTTLPR or 5-HTTVNTR and treatment response to venlafaxine. Methods: 84 Korean major depressive disorder patients were included in this study. They were administered $75 \mathrm{mg}$ of venlafaxine XR (extended release) for 1 week and then took $150 \mathrm{mg}$ for the next 3 weeks. All patients were evaluated at baseline and week 4 by the Hamilton Depression Rating Scale (HAM-D), Montgomery-Åsberg Depression Rating Scale (MADRS), Beck Depression Inventory (BDI), Hamilton Anxiety Rating Scale (HAM-A), and Beck Anxiety Inventory (BAI). Results: (1) Treatment response of depressive symptoms (BDI, HAM-D,
\end{abstract}

MADRS) to venlafaxine at week 4 was associated with the non-s/s (I/I and I/s) genotype of 5-HTTLPR; (2) in repeated measures ANOVA, the BDI, MADRS and HAM-A scores decreased more significantly in patients with the non-s/s genotype than in those with the $\mathrm{s} / \mathrm{s}$ genotype, and (3) multiple regression analyses suggested that the 5-HTTLPR polymorphism is a predictive factor for short-term treatment response to venlafaxine. However, 5-HTTVNTR showed no significant association with treatment response to venlafaxine. Both 5-HTTLPR and 5-HTTVNTR were not associated with side effects of venlafaxine. Conclusion: The 5-HTTLPR non$\mathrm{s} / \mathrm{s}$ genotype can be associated with venlafaxine treatment responses. However, further large-scale studies are warranted to confirm this finding.

Copyright $\odot 2010$ S. Karger AG, Basel

\section{Introduction}

In psychiatry, finding the predictors of antidepressant response is important in clinical practice. Given that the serotonin transporter can play a role in the functional modulation of serotonin, many researchers ask if poly-

\section{KARGER}

Fax +4161306 1234 E-Mail karger@karger.ch www.karger.com
(C) 2010 S. Karger AG, Basel

0302-282X/10/0623-0198\$26.00/0

Accessible online at:

www.karger.com/nps
Se Joo Kim

Department of Psychiatry and Institute of Behavioural Science in Medicine

Yonsei University College of Medicine, 250 Seongsan-no, Seodaemun-gu

Seoul 120-752 (South Korea)

Tel. +82 2228 1627, Fax +82 2313 0891, E-Mail kimsejoo@yuhs.ac 
morphisms of the serotonin transporter (5-HTT) gene could predict the treatment response to selective serotonin reuptake inhibitors (SSRI). To date, a number of studies about the relationship between several genetic variants in 5-HTT and treatment response to SSRI have been reported, but it is still controversial. Among those genetic variants of $5-\mathrm{HTT}$, the serotonin transporter linked promoter region (5-HTTLPR) polymorphism and 5-HTT intron 2 variable number tandem repeat (5HTTVNTR) are most widely studied.

Some researchers insist that the 1/1 genotype or 1-allele of the 5-HTTLPR gene is associated with treatment response to SSRI [1-3]. Corroboration by other researchers and meta-analysis also support these findings [4]. However, there also exist negative findings [5]. Moreover, in Asian studies, the direction of the effect of the 5HTTLPR polymorphism on treatment response to SSRI indicated contradictory results. Several studies [6-8] have shown that contrary to Caucasian populations, the s/s genotype or s-allele of 5-HTTLPR is associated with a better treatment response to SSRI. However, others [9] have shown that the $1 / 1$ genotype is associated with a better treatment response.

There are several reports regarding the association between 5-HTTLPR and SSRI side effects. Carriers of the s-allele treated with paroxetine exhibit reduced tolerability and higher discontinuation rates compared to $1 / 1$ homozygotes [10], and the s-variant was associated with side effects induced by SSRI [11]. Furthermore, the s-allele was shown to identify patients at risk for developing insomnia and agitation with fluoxetine treatment [12]. Other studies reported no association between 5-HTTLPR and adverse effects induced by SSRI $[13,14]$.

5-HTTVNTR has been addressed less than 5-HTTLPR. Min et al. [15] reported that depressive patients with the $12 / 12$ repeats of 5-HTTVNTR or the $1 / 1$ genotype of 5-HTTLPR experienced a better clinical response to SSRI or serotonin norepinephrine reuptake inhibitors (SNRI). One Korean study also showed that major depressive disorder (MDD) patients that were homozygous for $12 / 12$ repeats of 5-HTTVNTR or the s/s of 5-HTTLPR showed better responses than all others [7].

However, only a limited number of pharmacokinetic genetic studies reported the relationship between SNRI, which are frequently used in clinical practice, and serotonin transporter polymorphisms. No influence of 5HTTLPR polymorphisms on the antidepressant response to milnacipran was detected. In contrast, the presence of the $\mathrm{T}$ allele of the NET T-182C polymorphism was associated with a superior milnacipran response [16]. Recent- ly, two Japanese studies showed that the C allele of -1297 $\mathrm{C} \rightarrow \mathrm{G} \alpha_{2}$-adrenergic receptor and the Met/Met genotype of COMT Val158Met polymorphisms are associated with better or faster response to milnacipran $[17,18]$. And although the study sample did not consist of depressive patients, the response in venlafaxine-treated obsessivecompulsive disorder patients has been reported to be associated with the 1/s genotype of 5-HTTLPR [19]. Therefore, we investigated whether an association exists between venlafaxine and serotonin transporter gene polymorphisms in patients with MDD.

\section{Methods}

Subjects

A total of 101 patients with MDD were recruited from 3 general hospitals over a period of 24 months from July 2006 to December 2008. All the patients were Korean, met the DSM-IV criteria for MDD and were diagnosed by the Structural Clinical Interview for DSM-IV. Patients with other axis I disorders (including dementia, substance abuse, panic disorder, obsessivecompulsive disorder and generalized anxiety disorder) and those with axis II disorders, determined by a clinical interview, were excluded. Patients with a history of seizure, brain trauma, cardiovascular disorders or significant physical or neurological disorders were also excluded. The ages of the patients ranged from 20 to 69 years and all had been free of psychotropic drugs for at least 14 days prior to their entry into the study. All study procedures complied with the institutional review board regulations and were conducted in accordance with the Declaration of Helsinki and the principles of Good Clinical Practice. After a complete description of the study to the subjects, written informed consent was obtained.

During the treatment period, venlafaxine was administered to all patients daily (in the morning after breakfast at the same dose) for 4 weeks. The initial total dose was $75 \mathrm{mg} /$ day, which after 1 week was increased to $150 \mathrm{mg} /$ day. Additionally, administration of lorazepam $(0.5 \mathrm{mg})$ at bedtime was permitted once per week to patients with insomnia. No other psychotropic drugs were permitted during the study. All types of psychotherapies other than brief supportive psychotherapy were not permitted as well.

\section{Genotyping}

Peripheral blood was collected and genomic DNA extracted using standard procedures [20]. The region containing the 5HTTLPR polymorphism was amplified by PCR using the forward primer 5'-GGCGGTGCCGCTCTGAATGC-3' and the reverse primer 5'-GAGGGACTGAGCTGGACAACAAC-3', according to a previously described protocol [21]. The long (528 bp) and short (484 bp) PCR-amplified 5-HTTLPR alleles were separated by electrophoresis on $3 \%$ agarose gels supplemented with ethidium bromide and visualized by silver staining.

Genotyping of 5-HTTVNTR was carried out according to the method previously described [22]. The primers 8,224 (5'-GTCAGTATCACAGGCTGCGAG) and 8,223 (5'-TGTTCCTAGTCTTACGCCAGTG) were used. These primer pairs amplify across 
the VNTR region of intron 2 that contains the 17-bp repetitive element. PCR was performed in a final volume of $25 \mu$ l containing $50 \mathrm{ng}$ of genomic DNA, $0.2 \mathrm{mM}$ dNTPs, $10 \mathrm{pmol}$ of each primer, $10 \mathrm{mM}$ Tris- $\mathrm{HCl}$ (pH 8.3), $50 \mathrm{mM} \mathrm{KCl}, 1.5 \mathrm{mM} \mathrm{MgCl}_{2}, 0.01 \%$ gelatine and $1 \mathrm{U}$ of Taq DNA polymerase. The PCR amplification consisted of 35 cycles at $95^{\circ} \mathrm{C}(1 \mathrm{~min}), 58^{\circ} \mathrm{C}(1 \mathrm{~min})$ and $72^{\circ} \mathrm{C}$ ( $1 \mathrm{~min})$. Amplified fragments were resolved on $3 \%$ agarose gels, and bands were visualized by ethidium bromide staining and ultraviolet transillumination. The genotyping success rates for both 5-HTTLPR and 5-HTTVNTR were 100\%.

\section{Assessments}

The Hamilton Anxiety Rating Scale (HAM-A) [23], Beck Anxiety Inventory (BAI) [24], Hamilton Depression Rating Scale (HAM-D) [25], Montgomery-Åsberg Depression Rating Scale (MADRS) [26] and Beck Depression Inventory (BDI) [27] were used to evaluate patients at baseline, and after 1 and 4 weeks of treatment. The interrater reliability was $0.80-0.84$ for the HAMA and HAM-D.

Responders were defined by a reduction from baseline in the depressive or anxiety symptom scale score of at least $50 \%$, and remitters were defined by a HAM-D total score of 7 points or less after 4 weeks of treatment. We measured the side effects of venlafaxine treatment using the Toronto Side Effect Scale [28]. For each side effect, we classified the patients into a side effect group and a non-side-effect group. If the patients experienced any kinds of side effects at any time during the 4 treatment periods, we included them into the side effect group. Because of the limited statistical power, we compared the genotype and allelic differences between the 2 groups only in the side effects that occurred in more than $15 \%$ of the participants who completed this study.

Drug compliance was judged using a self-report checklist drawn up by each patient regarding their daily schedule and side effects of the medication. Capsule counting was also done during the study. According to the checklist and capsule counting, we excluded 4 patients that showed noncompliance more than twice a week.

\section{Data Analysis}

The Hardy-Weinberg equilibrium for genotype frequencies in MDD patients was calculated using $\chi^{2}$ tests. Of the remaining 84 patients, a small number of missing values on both the depressive and anxiety scales existed. Because of this small number, the values were not modified by intent to treat, such as the last-observation-carried-forward method. To consider the number of missing values from each scale, we tabulated the number of subjects who were used in the statistical analysis of each scale. Additionally, to confirm our data, we also used repeated measures ANOVA to find out the relationship between 0-, 1- and 4-week changes of each measurement over time and across genotypes. These factors were a main effect of time (which indicated whether changes in an outcome variable occurred as a function of time, irrespective of genotypes) and a time $\times$ treatment interaction (which indicated whether changes in subjects over time differed between genotypes). Categorical data were analyzed using the $\chi^{2}$ test. Odds ratios (OR) with a $95 \% \mathrm{CI}$ were calculated to estimate the effects of high-risk genotypes and alleles. Logistic regression analysis was used to determine the predictors of venlafaxine treatment response or remission. The cutoff probability value was set at 0.05 . SPSS (PC version 13) and was used for statistical analysis. This study had the power (0.8) to detect a medium effect size $(\mathrm{w}=0.33)$ between 2 genotypes (s/s vs. non-s/s) of 5-HTTLPR $(\alpha=0.05)$.

\section{Results}

\section{Sociodemographic Characteristics}

The sociodemographic characteristics of the MDD patients are listed as below: male/female ratio of $40(40 \%) / 61$ (60\%), and age of $44.6 \pm 17.0$ years. Each genotype distribution of the 5-HTTLPR and 5-HTTVNTR polymorphism genotypes was in Hardy-Weinberg equilibrium (all $\mathrm{p}>0.05$ ).

A total of 101 subjects with MDD had been recruited. Twenty-three patients (22\%) were comorbid with dysthymic disorders. Twenty-nine patients (29\%) had disorders of the melancholic type, and 5 patients (5\%) had atypical types. Of the 101 patients enrolled, $17 \mathrm{did}$ not complete the study: 8 patients because of side effects, 1 patient because of inefficacy, 4 patients because of partial compliance as determined by a compliance checklist and 4 patients without explanation. Eighty-four MDD patients remained in this study. The baseline scores for age, sex and initial HAM-D between patients who dropped out and those remaining in this study at 4 weeks were not significantly different.

\section{Venlafaxine Short-Term Treatment Response and Genotype Distribution of 5-HTTLPR Polymorphism}

There were significant differences in the 5-HTTLPR genotype distribution between responders and nonresponders divided by HAM-D $\left(\chi^{2}=7.5 ; \mathrm{p}=0.006\right)$, MADRS $\left(\chi^{2}=11.7 ; \mathrm{p}=0.0006\right)$ and BDI $\left(\chi^{2}=6.0 ; \mathrm{p}=0.01\right)$ at 4 weeks. That is, the non-s/s genotype showed a significant association with responders for each of the 4-week scale scores (table 1). There was also a significant difference in the 5-HTTLPR genotype distribution between responders and nonresponders divided by HAM-A at 4 weeks $\left(\chi^{2}=7.5 ; \mathrm{p}=0.006\right)$. However, no significant difference existed between responders and nonresponders by BAI $\left(\chi^{2}=7.5 ; \mathrm{p}=0.006\right)$ (table 2$)$. To consider the 0 -, 1 - and 4 -week serial changes of measurements over time, repeated measures ANOVA was also used and showed significant genotype $\times$ time interaction in 3 scales, BDI $(\mathrm{F}=$ 3.4; d.f. $=2,162 ; \mathrm{p}=0.03)$, MADRS ( $\mathrm{F}=15$; d.f. $=2,156$; $\mathrm{p}<0.001)$ and HAM-A $(\mathrm{F}=4.5$; d.f. $=2,152 ; \mathrm{p}=0.01)$ between non-s/s genotype and s/s genotype after the time effects were significantly shown in all each scales $(F=39$, 
Table 1. Venlafaxine treatment response of depressive symptoms and genotype and allele frequencies of the 5-HTTLPR polymorphism in patients with MDD

\begin{tabular}{|c|c|c|c|c|}
\hline & \multicolumn{4}{|c|}{ Genotype, $\mathrm{n}$} \\
\hline & $1 / 1$ & $1 / \mathrm{s}$ & non-s/s & $\mathrm{s} / \mathrm{s}$ \\
\hline \multicolumn{5}{|l|}{ BDI } \\
\hline Responder $(\mathrm{n}=42)$ & $4(9)$ & $18(43)$ & $22(52)$ & $20(47)$ \\
\hline \multirow[t]{2}{*}{ Nonresponder $(\mathrm{n}=42)$} & $1(2)$ & $10(24)$ & $11(26)$ & $31(74)$ \\
\hline & & & \multicolumn{2}{|c|}{$\begin{array}{l}\chi^{2}=6.0, \text { d.f. }=1, p=0.01 \\
\mathrm{OR}=3.10, \mathrm{CI}=1.24-7.75\end{array}$} \\
\hline \multicolumn{5}{|l|}{ HAM-D } \\
\hline Responder $(\mathrm{n}=54)$ & $4(7)$ & $23(43)$ & $27(50)$ & $27(50)$ \\
\hline \multirow[t]{2}{*}{ Nonresponder $(\mathrm{n}=27)$} & $0(0)$ & 5 (19) & $5(19)$ & $22(81)$ \\
\hline & & & \multicolumn{2}{|c|}{$\begin{array}{l}\chi^{2}=7.5, \text { d.f. }=1, \mathrm{p}=0.006 \\
\mathrm{OR}=4.40, \mathrm{CI}=1.45-13.32\end{array}$} \\
\hline \multicolumn{5}{|l|}{ MADRS } \\
\hline Responder $(\mathrm{n}=47)$ & $2(4)$ & $24(51)$ & $26(56)$ & $21(45)$ \\
\hline \multirow[t]{2}{*}{ Nonresponder $(\mathrm{n}=34)$} & $2(6)$ & $4(12)$ & $6(18)$ & $28(82)$ \\
\hline & & & \multicolumn{2}{|c|}{$\begin{array}{l}\chi^{2}=11.7, \text { d.f. }=1, p=0.0006 \\
\mathrm{OR}=5.78, \mathrm{CI}=2.02-16.56\end{array}$} \\
\hline
\end{tabular}

Values in parentheses denote percentages.

Table 2. Venlafaxine treatment response of anxiety symptoms and genotype and allele frequencies of the 5HTTLPR polymorphism in patients with MDD

\begin{tabular}{|c|c|c|c|c|}
\hline & \multicolumn{4}{|c|}{ Genotype, $\mathrm{n}$} \\
\hline & $1 / 1$ & $1 / \mathrm{s}$ & non-s/s & $\mathrm{s} / \mathrm{s}$ \\
\hline \multicolumn{5}{|l|}{ BAI } \\
\hline Responder $(n=47)$ & $3(6)$ & $19(40)$ & $22(46)$ & $25(54)$ \\
\hline Nonresponder $(n=36)$ & $2(5)$ & $8(22)$ & $10(27)$ & $26(73)$ \\
\hline & & & \multicolumn{2}{|c|}{$\begin{array}{l}\chi^{2}=3.11, \text { d.f. }=1, \mathrm{p}=0.08 \\
\mathrm{OR}=2.29, \mathrm{CI}=0.91-5.78\end{array}$} \\
\hline \multicolumn{5}{|l|}{ HAM-A } \\
\hline Responder $(\mathrm{n}=52)$ & $4(7)$ & $23(43)$ & $27(50)$ & $27(50)$ \\
\hline \multirow[t]{2}{*}{ Nonresponder $(n=27)$} & $0(0)$ & $5(19)$ & $5(19)$ & $22(81)$ \\
\hline & & & \multicolumn{2}{|c|}{$\begin{array}{l}\chi^{2}=7.5, \text { d.f. }=1, p=0.006 \\
O R=4.40, C I=1.45-13.32\end{array}$} \\
\hline
\end{tabular}

Values in parentheses denote percentages.

d.f. $=2,162, p<0.001 ; \mathrm{F}=59$, d.f. $=2,156, \mathrm{p}<0.001 ; \mathrm{F}=$ 178 , d.f. $=2,152, \mathrm{p}<0.001$, respectively). That is, the scores of the BDI, MADRS and HAM-A significantly decreased in patients with the non-s/s genotype $\times$ time interaction type compared to those with the s/s genotype.
In terms of the HAM-D, a trend-level genotype $\times$ time interaction showed ( $\mathrm{F}=2$; d.f. $=2,160 ; \mathrm{p}=0.07)$ after the time effects had been significant $(\mathrm{F}=303$; d.f. $=2,160$; $\mathrm{p}<0.001$ ) (table 3). However, there is no association between 5-HTTVNTR and short-term treatment response 
Table 3. Differences in depressive and anxiety symptom severity between s/s and non-s/s genotypes of 5-HTTLPR at baseline, week 1 and week 4 (scores)

\begin{tabular}{|c|c|c|c|c|c|c|}
\hline & \multicolumn{2}{|l|}{ Week 0} & \multicolumn{2}{|l|}{ Week 1} & \multicolumn{2}{|l|}{ Week 4} \\
\hline & $\mathrm{s} / \mathrm{s}$ & non-s/s & $\mathrm{s} / \mathrm{s}$ & non-s/s & $\mathrm{s} / \mathrm{s}$ & non-s/s \\
\hline BDI & $31.40 \pm 11.63$ & $30.46 \pm 12.65$ & $24.87 \pm 11.36$ & $21.24 \pm 8.19$ & $18.34 \pm 14.00$ & $12.03 \pm 8.77$ \\
\hline MADRS & $33.85 \pm 7.03$ & $35.56 \pm 10.32$ & $26.16 \pm 8.53$ & $23.17 \pm 6.80$ & $18.45 \pm 11.58$ & $10.78 \pm 8.24$ \\
\hline HAM-D & $28.19 \pm 7.02$ & $27.06 \pm 6.56$ & $20.83 \pm 6.67$ & $18.17 \pm 5.20$ & $13.48 \pm 8.54$ & $9.28 \pm 6.68$ \\
\hline BAI & $30.42 \pm 17.39$ & $26.38 \pm 14.84$ & $24.14 \pm 13.79$ & $18.56 \pm 10.93$ & $17.86 \pm 14.76$ & $10.75 \pm 9.49$ \\
\hline HAM-A & $26.60 \pm 9.23$ & $24.65 \pm 8.39$ & $20.49 \pm 7.93$ & $16.23 \pm 5.82$ & $14.38 \pm 9.44$ & $7.81 \pm 5.91$ \\
\hline
\end{tabular}

Values are means $\pm \mathrm{SD}$.

Table 4. Venlafaxine treatment response of depressive and anxiety symptoms and genotype distribution of the 5-HTTVNTR polymorphism in patients with MDD

\begin{tabular}{|c|c|c|c|}
\hline & \multicolumn{2}{|c|}{ Genotype, n } & \multirow[t]{2}{*}{$\chi^{2}$ and $\mathrm{OR}$} \\
\hline & $12 / 12$ & non-12/12 & \\
\hline \multicolumn{4}{|l|}{ BDI } \\
\hline Responder $(n=42)$ & $36(85)$ & $6(15)$ & $\chi^{2}=0.24$, d.f. $=1, p=0.55$ \\
\hline Nonresponder $(\mathrm{n}=42)$ & $34(81)$ & $8(19)$ & $\widehat{\mathrm{OR}}=1.41, \mathrm{CI}=0.44-4.49$ \\
\hline \multicolumn{4}{|l|}{ HAM-D } \\
\hline Responder $(\mathrm{n}=55)$ & $47(85)$ & $8(15)$ & $\chi^{2}=0.23$, d.f. $=1, p=0.63$ \\
\hline Nonresponder $(\mathrm{n}=28)$ & $25(89)$ & $3(11)$ & $\widehat{\mathrm{OR}}=0.71, \mathrm{CI}=0.17-2.90$ \\
\hline \multicolumn{4}{|l|}{ MADRS } \\
\hline Responder $(n=47)$ & $39(83)$ & $8(17)$ & $\chi^{2}=1.10$, d.f. $=1, p=0.28$ \\
\hline Nonresponder $(\mathrm{n}=34)$ & $31(91)$ & $3(9)$ & $\mathrm{OR}=0.47, \mathrm{CI}=0.12-1.93$ \\
\hline \multicolumn{4}{|l|}{ BAI } \\
\hline Responder $(n=47)$ & $38(81)$ & $9(19)$ & $\chi^{2}=0.40$, d.f. $=1, p=0.53$ \\
\hline Nonresponder $(n=36)$ & $31(86)$ & $5(14)$ & $\mathrm{OR}=0.68, \mathrm{CI}=0.21-2.24$ \\
\hline \multicolumn{4}{|l|}{ HAM-A } \\
\hline Responder $(\mathrm{n}=53)$ & $46(87)$ & $7(13)$ & $\chi^{2}=0.02$, d.f. $=1, p=0.89$ \\
\hline Nonresponder $(\mathrm{n}=28)$ & $24(86)$ & $4(14)$ & $\hat{\mathrm{OR}}=1.10, \mathrm{CI}=0.29-4.12$ \\
\hline
\end{tabular}

Values in parentheses denote percentages.

to venlafaxine by both $\chi^{2}$ analysis (table 4 ) and repeated measures ANOVA; BDI $(F=2.05$; d.f. $=1,83 ; \mathrm{p}=0.16)$, BAI $(\mathrm{F}=0.66$; d.f. $=1,83 ; \mathrm{p}=0.42)$, MADRS $(\mathrm{F}=3.24$; d.f. $=1,78 ; \mathrm{p}=0.08)$, HAM-D $(\mathrm{F}=2.44$; d.f. $=1,80 ; \mathrm{p}=$ $0.12)$ and HAM-A $(\mathrm{F}=2.01$; d.f. $=1,78 ; \mathrm{p}=0.16)$. There also was no significant difference in the genotype distributions of 5-HTTLPR or 5-HTTVNTR between remitters and nonremitters at 4 weeks (table 5).

The total number of subjects who experienced any kind of side effect during the 4-week treatment period was 60 (71.43\%). The side effects reported in more than $15 \%$ of the subjects were as follows: gastrointestinal $(\mathrm{n}=$
29; 34.52\%); sexual ( $\mathrm{n}=18 ; 21.43 \%)$; nose, mouth and throat $(\mathrm{n}=17 ; 20.24 \%)$; neurological $(\mathrm{n}=15 ; 17.86 \%)$ and sleep related $(\mathrm{n}=13 ; 15.48 \%)$. There were no significant associations between 5-HTTLPR or 5-HTTVNTR and those side effects (all $\mathrm{p}>0.05$; data not presented).

\section{Prediction of Venlafaxine Treatment Response at 4 \\ Weeks Using Logistic Regression Analysis}

Table 5 summarizes the results of the logistic regression analysis, illustrating the possibility of using the 5-HTTLPR genotype as a predictor of venlafaxine treatment response. Multivariate logistic regression analyses 
Table 5. Remission state by HAM-D and genotype distributions of 5-HTTLPR and 5-HTTVNTR

\begin{tabular}{|c|c|c|c|c|}
\hline & \multicolumn{4}{|c|}{ Genotype, $\mathrm{n}$} \\
\hline & $1 / 1$ & $1 / \mathrm{s}$ & non-s/s & $\mathrm{s} / \mathrm{s}$ \\
\hline \multicolumn{5}{|l|}{ 5-HTTLPR } \\
\hline Remitter $(n=26)$ & $2(6)$ & $12(40)$ & $14(46)$ & $22(54)$ \\
\hline \multirow[t]{3}{*}{ Nonremitter $(\mathrm{n}=58)$} & $2(5)$ & $16(22)$ & $18(27)$ & $40(73)$ \\
\hline & & & \multicolumn{2}{|c|}{$\begin{array}{l}\chi^{2}=0.61, \text { d.f. }=1, \mathrm{p}=0.43 \\
\mathrm{OR}=1.41, \mathrm{CI}=0.60-3.35\end{array}$} \\
\hline & & & $12 / 12$ & non- $12 / 12$ \\
\hline \multicolumn{5}{|l|}{ 5-HTTVNTR } \\
\hline Remitter $(\mathrm{n}=26)$ & & & $20(77)$ & $6(23)$ \\
\hline \multirow[t]{2}{*}{ Nonremitter $(\mathrm{n}=58)$} & & & $51(88)$ & $7(12)$ \\
\hline & & & \multicolumn{2}{|c|}{$\begin{array}{l}\chi^{2}=1.6, \text { d.f. }=1, p=0.20 \\
\mathrm{OR}=2.19, \mathrm{CI}=0.65-7.31\end{array}$} \\
\hline
\end{tabular}

Values in parentheses denote percentages.

Table 6. Prediction of venlafaxine treatment response using logistic regression analysis

\begin{tabular}{|c|c|c|c|c|c|}
\hline & $\mathrm{R}^{2}$ & $\beta$ & d.f. & $\mathrm{p}$ & OR \\
\hline \multicolumn{6}{|l|}{ BDI } \\
\hline Genotype & 0.17 & 1.0 & 1 & 0.02 & 0.3 \\
\hline BDI-0w & & 0.04 & 1 & 0.03 & 1.0 \\
\hline Sex; age & & $0.1 ; 0.0$ & 1 & NS & $0.8 ; 0.9$ \\
\hline \multicolumn{6}{|l|}{ HAM-D } \\
\hline Genotype & 0.23 & 1.7 & 1 & 0.00 & 0.17 \\
\hline Sex; age; HAM-D-0w & & $0.5 ; 0.1 ; 0.1$ & 1 & NS & $1.7 ; 0.9 ; 1.0$ \\
\hline \multicolumn{6}{|l|}{ MADRS } \\
\hline Genotype & 0.29 & 1.1 & 1 & 0.02 & 0.3 \\
\hline Sex & & 1.3 & 1 & 0.02 & 0.27 \\
\hline Age; MADRS-0w & & $0.02 ; 0.01$ & 1 & NS & $0.9 ; 0.9$ \\
\hline \multicolumn{6}{|l|}{ HAM-A } \\
\hline Genotype & 0.28 & 2.1 & 1 & 0.00 & 0.01 \\
\hline Sex; age; HAM-A-0w & & $0.5 ; 0.0 ; 0.0$ & 1 & NS & 1 \\
\hline
\end{tabular}

0w $=$ Score at week 0 ; NS = not significant.

utilized venlafaxine treatment response according to depressive scales such as the BDI, HAM-D and MADRS as dependent variables and with variables showing a significant correlation with the treatment response of each scale as covariates. The results revealed a significant association of the 5-HTTLPR genotype distribution with treatment response on all scales (table 6).

Serotonin Transporter Polymorphism and Venlafaxine

\section{Discussion}

The purpose of this study was to determine the relationship between the 5-HTT polymorphisms and venlafaxine treatment response. Since the 5-HTT polymorphisms, especially 5-HTTLPR, have been suggested to be predictors of SSRI treatment response, and given that venlafaxine is a potent inhibitor of serotonergic reuptake, 
a hypothesis that venlafaxine treatment response could be related to a 5-HTT polymorphism has been put forth. Our results indicate that the non-s/s genotype $(1 / 1+1 / s)$ of the 5-HTTLPR polymorphism might be associated with better short-term treatment response to venlafaxine. These results are supported by previous reports that the non-s/s genotype is associated with good treatment response [4]. The mechanism behind these results can be assumed according to the following findings. First, the capability of the l-allele lymphoblast with respect to serotonin transport is twice as high as that of the s-allele lymphoblast [29], and transcriptional activity, which is regulated by protein kinase $\mathrm{A}$ or $\mathrm{C}$, is better in l-allele plasma platelets [30]. Secondly, transport efficacy $\left(\mathrm{V}_{\max } / \mathrm{K}_{\mathrm{m}}\right)$, which is the maximum velocity of serotonin transport per substrate utilization, is lower in subjects with the sallele [29]. Thirdly, proinflammatory cytokines, which promote the expression of the serotonin transporter, can be activated in the presence of the l-allele [31].

In contrast, some researchers have reported that the $\mathrm{s} / \mathrm{s}$ genotype or s-allele is associated with good treatment response to SSRI, especially in Asian populations [7, 8]. Others could not find any significant association between 5-HTTLPR and treatment response to SSRI [5]. The discrepancy between those findings and our results may stem from the following. First, since the mechanisms of action of the SNRI, the treatment response to venlafaxine can be different from the response to SSRI, as in the milnacipran report [16]. Second, differences in ethnicity, symptom severity, duration of treatment, and time points of assessment between this study and previous studies could also be a source of inconsistent results. Recently, Mrazek et al. [3] found that the $1 / 1$ genotype had a greater likelihood of remission after citalopram treatment in only white non-Hispanic subjects but not in white Hispanic or black subjects. Similar to our study, some other Asian studies showed the association between the non-s/s or 1 allele of 5-HTTLPR and good response to SSRI [9, 15, 32]. Considering these inconsistent results, further studies using larger sample sizes in various ethnic populations are required in order to verify this relationship.

Although the number of subjects in our study is small, our results suggest that 5-HTTLPR polymorphism can act as a predictor of venlafaxine treatment response. Our study indicated that the side effects of venlafaxine were not associated with 5-HTTLPR or genotype distribution. This result is consistent with previous studies $[13,14]$ that reported no association between the 5-HTTLPR and side effects of SRIs. However, a recent meta-analysis [33] suggested the strong relationship between 5-HTTLPR and side effects of SSRIs. This discrepancy might come from different ethnicities or the different kinds of anti-depressants (mainly SSRIs vs. venlafaxine) used in studies. In addition, because the sample size in our study is much smaller than that study, our study could not have enough power to detect such an association between 5-HTTLPR and side effects.

In this study, 5-HTTVNTR genotypes showed no significant association with treatment response. This result is partially in line with previous reports $[34,35]$. However, a meta-analysis [33] reported that the 12/12 genotype showed a trend toward a better response in Asians. Recently, Mrazek et al. [3] reported that in white nonHispanic subjects, 5-HTTVNTR was associated with remission following treatment with citalopram. However, they also could not find any association between 5-HTTVNTR and remission in white, Hispanic or black subjects. Those findings suggest that the genetic effects of 5-HTTVNTR on the response or adverse reaction to antidepressants can be different according to study populations. However, some Korean studies also reported the association between the 1/1 genotype of 5-HTTVNTR and better response to SSRI [7] although they did not use venlafaxine. Therefore, further investigations of large samples in various populations are needed.

This study has several limitations. First, due to the limited number of subjects in the study population, the present study can only be regarded as a pilot study and it should be replicated in a larger sample. Considering the small number of subjects who were remitted on the 4th week or who experienced side effects, we could not find any association between the two genes and remission or side effects due to the insufficient statistical power of this study. Second, this study only evaluated short-term treatment responses in MDD patients after 4 weeks of drug administration. However, since a systemic analysis suggested that early treatment response can extend to longterm treatment response, some researchers have insisted that 4 weeks is enough to establish treatment response [36]. Third, we analyzed only two single-nucleotide polymorphisms (SNPs) of 5-HTTLPR and 5-HTTVNTR. However, other variants such as a functional SNP rs25531 have been reported to be associated with treatment response [37]. Therefore, further large-scale studies using tag SNPs which cover the entire gene region as well as the other variations that are supposed to have functional implications are needed. Fourth, we evaluated a relatively low dose (fixed dose of $150 \mathrm{mg}$ ) for venlafaxine treatment response; however, it is known that the serotonergic activity of venlafaxine is potent at a relatively low dose [38, 
39], and so we thought that $150 \mathrm{mg}$ would be sufficient to evaluate the relationship between the serotonergic gene, 5-HTTLPR, and treatment response. Fifth, the association of 5-HTTLPR with venlafaxine response should be examined in a placebo-controlled study. We cannot rule out the presence of a population-based stratification bias in the present study. Finally, plasma levels of venlafaxine were not analyzed in these patients. Thus, we do not know exactly the conditions of the drug metabolism. Although we excluded poor drug compliance by a self-re- port checklist, there might potentially be additional noncompliant patients in this study.

In conclusion, this study has demonstrated that the non-s/s $(1 / s+1 / 1) 5$-HTTLPR genotype is associated with, and can act as a predictor of, better treatment response to venlafaxine. However, these findings require confirmation via well-designed studies utilizing larger samples before 5-HTTLRP genotyping is considered in the routine clinical evaluation of MDD patients using venlafaxine.

\section{References}

1 Pollock BG, Ferrell RE, Mulsant BH, Mazumdar S, Miller M, Sweet RA, Davis S, Kirshner MA, Houck PR, Stack JA, Reynolds CF, Kupfer DJ: Allelic variation in the serotonin transporter promoter affects onset of paroxetine treatment response in latelife depression. Neuropsychopharmacology 2000;23:587-590

-2 Smeraldi E, Zanardi R, Benedetti F, di Bella $\mathrm{D}$, Perez J, Catalano M: Polymorphism within the promoter of the serotonin transporter gene and antidepressant efficacy of fluvoxamine. Mol Psychiatry 1998;3:508-511.

-3 Mrazek DA, Rush AJ, Biernacka JM, O'Kane DJ, Cunningham JM, Wieben ED, Schaid DJ, Drews MS, Courson VL, Snyder KA, Black JL 3rd, Weinshilboum RM: SLC6A4 variation and citalopram response. Am J Med Genet B Neuropsychiatr Genet 2009;150B:341-351.

-4 Serretti A, Kato M, de Ronchi D, Kinoshita T: Meta-analysis of serotonin transporter gene promoter polymorphism (5-HTTLPR) association with selective serotonin reuptake inhibitor efficacy in depressed patients. Mol Psychiatry 2007;12:247-257.

-5 Maron E, Tammiste A, Kallassalu K, Eller T, Vasar V, Nutt DJ, Metspalu A: Serotonin transporter promoter region polymorphisms do not influence treatment response to escitalopram in patients with major depression. Eur Neuropsychopharmacol 2009; 19:451-456

-6 Kim H, Lim SW, Kim S, Kim JW, Chang YH, Carroll BJ, Kim DK: Monoamine transporter gene polymorphisms and antidepressant response in Koreans with late-life depression. JAMA 2006;296:1609-1618.

$\checkmark 7$ Kim DK, Lim SW, Lee S, Sohn SE, Kim S, Hahn CG, Carroll BJ: Serotonin transporter gene polymorphism and antidepressant response. Neuroreport 2000;11:215-219.
8 Yoshida K, Ito K, Sato K, Takahashi H, Kamata $\mathrm{M}$, Higuchi $\mathrm{H}$, Shimizu T, Itoh $\mathrm{K}$, Inoue K, Tezuka T, Suzuki T, Ohkubo T, Sugawara $\mathrm{K}$, Otani K: Influence of the serotonin transporter gene-linked polymorphic region on the antidepressant response to fluvoxamine in Japanese depressed patients. Prog Neuropsychopharmacol Biol Psychiatry 2002;26: 383-386.

9 Yu YW, Tsai SJ, Chen TJ, Lin CH, Hong CJ: Association study of the serotonin transporter promoter polymorphism and symptomatology and antidepressant response in major depressive disorders. Mol Psychiatry 2002;7:1115-1119.

10 Murphy GM Jr, Hollander SB, Rodrigues HE, Kremer C, Schatzberg AF: Effects of the serotonin transporter gene promoter polymorphism on mirtazapine and paroxetine efficacy and adverse events in geriatric major depression. Arch Gen Psychiatry 2004;61: 1163-1169.

11 Smits K, Smits L, Peeters F, Schouten J, Janssen R, Smeets H, van Os J, Prins M: Serotonin transporter polymorphisms and the occurrence of adverse events during treatment with selective serotonin reuptake inhibitors. Int Clin Psychopharmacol 2007;22:137-143.

12 Kronenberg S, Apter A, Brent D, Schirman S, Melhem N, Pick N, Gothelf D, Carmel M, Frisch A, Weizman A: Serotonin transporter polymorphism (5-HTTLPR) and citalopram effectiveness and side effects in children with depression and/or anxiety disorders. J Child Adolesc Psychopharmacol 2007;17: 741-750.

13 Kato M, Fukuda T, Wakeno M, Fukuda K, Okugawa G, Ikenaga Y, Yamashita M, Takekita Y, Nobuhara K, Azuma J, Kinoshita T: Effects of the serotonin type 2A, 3A and 3B receptor and the serotonin transporter genes on paroxetine and fluvoxamine efficacy and adverse drug reactions in depressed Japanese patients. Neuropsychobiology 2006;53:186195.
$14 \mathrm{NgCH}$, Easteal S, Tan S, Schweitzer I, Ho BK, Aziz S: Serotonin transporter polymorphisms and clinical response to sertraline across ethnicities. Prog Neuropsychopharmacol Biol Psychiatry 2006;30:953-957.

15 Min W, Li T, Ma X, Li Z, Yu T, Gao D, Zhang B, Yun Y, Sun X: Monoamine transporter gene polymorphisms affect susceptibility to depression and predict antidepressant response. Psychopharmacology (Berl) 2009; 205:409-417.

16 Yoshida K, Takahashi H, Higuchi H, Kamata M, Ito K, Sato K, Naito S, Shimizu T, Itoh K, Inoue K, Suzuki T, Nemeroff CB: Prediction of antidepressant response to milnacipran by norepinephrine transporter gene polymorphisms. Am J Psychiatry 2004;161:15751580

17 Wakeno M, Kato M, Okugawa G, Fukuda T, Hosoi Y, Takekita Y, Yamashita M, Nonen S, Azuma J, Kinoshita T: The $\alpha_{2 \mathrm{~A}}$-adrenergic receptor gene polymorphism modifies antidepressant responses to milnacipran. J Clin Psychopharmacol 2008;28:518-524.

18 Yoshida K, Higuchi H, Takahashi H, Kamata $\mathrm{M}$, Sato K, Inoue K, Suzuki T, Itoh K, Ozaki $\mathrm{N}$ : Influence of the tyrosine hydroxylase Val$81 \mathrm{Met}$ polymorphism and catechol-O-methyltransferase Val158Met polymorphism on the antidepressant effect of milnacipran. Hum Psychopharmacol 2008;23:121-128.

19 Denys D, van Nieuwerburgh F, Deforce D, Westenberg HG: Prediction of response to paroxetine and venlafaxine by serotonin-related genes in obsessive-compulsive disorder in a randomized, double-blind trial. J Clin Psychiatry 2007;68:747-753.

20 Lahiri DK, Nurnberger JI Jr: A rapid nonenzymatic method for the preparation of HMW DNA from blood for RFLP studies. Nucleic Acids Res 1991;19:5444

21 Heils A, Teufel A, Petri S, Stöber G, Riederer P, Bengel D, Lesch KP: Allelic variation of human serotonin transporter gene expression. J Neurochem 1996;66:2621-2624. 
-22 Ogilvie AD, Battersby S, Bubb VJ, Fink G, Harmar AJ, Goodwim GM, Smith CA: Polymorphism in serotonin transporter gene associated with susceptibility to major depression. Lancet 1996;347:731-733.

23 Hamilton M: The assessment of anxiety states by rating. Br J Med Psychol 1959;32: $50-55$.

24 Beck AT, Epstein N, Brown G, Steer RA: An inventory for measuring clinical anxiety: psychometric properties. J Consult Clin Psychol 1988;56:893-897.

25 Hamilton M: Development of a rating scale for primary depressive illness. Br J Soc Clin Psychol 1967;6:278-296.

-26 Peyre F, Martinez R, Calache M, Verdoux H, Bourgeois M: New validation of the Montgomery and Åsberg Depression Scale (MADRS) on a sample of 147 hospitalized depressed patients (in French). Ann Med Psychol (Paris) 1989;147:762-767.

-27 Beck AT, Beamesderfer A: Assessment of depression: the depression inventory. Mod Probl Pharmacopsychiatry 1974;7:151-169.
28 Vanderkooy JD, Kennedy SH, Bagby RM: Antidepressant side effects in depression patients treated in a naturalistic setting: a study of bupropion, moclobemide, paroxetine, sertraline, and venlafaxine. Can J Psychiatry 2002;47:174-180.

29 Rausch JL, Johnson ME, Fei YJ, Li JQ, Shendarkar N, Hobby HM, Ganapathy V, Leibach FH: Initial conditions of serotonin transporter kinetics and genotype: influence on SSRI treatment trial outcome. Biol Psychiatry 2002;51:723-732.

-30 Ramamoorthy S, Blakely RD: Phosphorylation and sequestration of serotonin transporters differentially modulated by psychostimulants. Science 1999;285:763-766.

31 Kubera M, Lin AH, Kenis G, Bosmans E, van Bockstaele D, Maes M: Anti-inflammatory effects of antidepressants through suppression of the interferon- $\gamma /$ interleukin-10 production ratio. J Clin Psychopharmacol 2001; 21:199-206.

32 Lee MS, Lee HY, Lee HJ, Ryu SH: Serotonin transporter promoter gene polymorphism and long-term outcome of antidepressant treatment. Psychiatr Genet 2004;14:111-115.

33 Kato M, Serretti A: Review and meta-analysis of antidepressant pharmacogenetic findings in major depressive disorder. Mol Psychiatry 2008, E-pub ahead of print.
34 Peters EJ, Slager SL, McGrath PJ, Knowles JA, Hamilton SP: Investigation of serotoninrelated genes in antidepressant response. Mol Psychiatry 2004;9:879-889.

35 Hong CJ, Chen TJ, Yu YW, Tsai SJ: Response to fluoxetine and serotonin $1 \mathrm{~A}$ receptor $(\mathrm{C}-$ 1019G) polymorphism in Taiwan Chinese major depressive disorder. Pharmacogenomics J 2006;6:27-33.

36 Taylor MJ, Freemantle N, Geddes JR, Bhagwagar Z: Early onset of selective serotonin reuptake inhibitor antidepressant action: systematic review and meta-analysis. Arch Gen Psychiatry 2006;63:1217-1223.

- 37 Kraft JB, Slager SL, McGrath PJ, Hamilton SP: Sequence analysis of the serotonin transporter and associations with antidepressant response. Biol Psychiatry 2005;58:374-381.

38 Wellington K, Perry CM: Venlafaxine extended-release: a review of its use in the management of major depression. CNS Drugs 2001;15:643-669.

39 Pan JJ, Shen WW: Serotonin syndrome induced by low-dose venlafaxine. Ann Pharmacother 2003;37:209-211. 